\title{
ELEMENTOS DO FILME PUBLICITÁRIO: A construção do sentido crazy
}

\section{ELEMENTS OF THE ADVERTISING FILM: The construction of the meaning Crazy}

Carlos Augusto Alfeld Rodrigues PUC/SP - Pontifícia Universidade Católica de São Paulo

Resumo: O presente artigo analisa, na publicidade audiovisual, os efeitos de sentido usados para construir a sua significação. Trata-se do exame da peça publicitária da Nissan - marca de automóveis e utilitários esportivos - que faz parte da campanha Crazy. O objeto de análise é o filme publicitário de 30 segundos veiculado na televisão em março de 2007. O filme publicitário é um texto sincrético por reunir vários tipos de linguagens: verbal, musical, visual. Esse sincretismo é compreendido na semiótica discursiva pelo plano do conteúdo e pelo plano da expressão, sendo que é na homologação dos planos que a significação pode ser depreendida.

Palavras-chave: audiovisual; publicidade; sentido; semiótica discursiva; sincretismo.

Abstract: The present article analyzes in the audiovisual publicity the sense effects used to build his meaning. It is the exam of the advertising of Nissan - mark of automobiles and utilitarian sporting - that does part of the campaign Crazy. The analysis object is the advertising film of 30 seconds transmitted in television in March of 2007. The advertising film is a text syncretic for gathering several types of languages: verbal, musical, visual. That syncretism is understood in the discoursive semiotics by the plan of the content and for the plan of the expression, and it is in the approval of the plans that the significance can be understood.

Keywords: audiovisual; advertisement; meaning; discoursive semiotics; syncretism

\section{Introdução}

Esta análise objetiva tratar da publicidade audiovisual, mais precisamente dos efeitos de sentido usados para construir a sua significação. Trata-se da análise da peça publicitária da Nissan - marca de automóveis e utilitários esportivos - que faz parte da 
campanha Crazy. Essa campanha publicitária conta com anúncios em televisão, mídia impressa (revista e outdoor) e internet.

O filme publicitário tem duração de 30 segundos. No site ${ }^{1}$ da campanha podemos assistir a uma versão apresentada com a duração de 1 minuto. No entanto, para que o filme publicitário se encaixe no formato dos comerciais convencionais com duração de 30 segundos foram feitos alguns cortes por meio dos recursos de edição. Dessa maneira o filme de 1 minuto foi reduzido para uma publicidade de 30 segundos. Sendo assim, o objeto de análise é o filme publicitário de 30 segundos veiculado na televisão em março de 2007.

Este estudo se faz necessário e pertinente tendo em vista que, praticamente todas as campanhas publicitárias de automóveis e, principalmente, as campanhas de lançamento utilizam a mídia televisual para veicular os seus filmes. De acordo com Floch (1993, p. 159) "el spot televisivo es el medio más significativo en la comunicación del automóvil". E complementa: "el medio televisivo se encuentra en perfecta adecuación con el automóvil".

Antes de iniciar a análise da publicidade, faço menção ao importante conceito de sincretismo de que o filme publicitário faz uso. O filme publicitário é tomado como um texto sincrético por reunir "várias linguagens ou diferentes formas de expressão como verbais, musicais, visuais para produzir um único todo de sentido" (LÓPES \& HERNANDES, 2005, p. 228). Esse sincretismo de linguagens na semiótica é compreendido pelo plano do conteúdo e pelo plano da expressão, sendo que é na homologação dos planos que a significação pode ser depreendida.

\section{O filme publicitário}

Primeiramente atentamos para a razão de ser da publicidade que:

não é unicamente fazer comprar este ou aquele produto. Antes disso, sua tarefa é criar no público uma disposição afetiva mais difusa, um desejo em estado puro, que condiciona a passagem ao ato, ou seja, à compra. Ora, o que faz desejar é, antes de tudo, o desejo do outro, a perturbação, contagiosa, que um corpo comovido deixa transparecer. (LANDOWSKI, 2006, p.14)

A publicidade usa de recursos sensíveis e inteligíveis para nos fazer desejar algo. Esse desejo, em pouco tempo, torna-se uma necessidade; essa necessidade é temporariamente satisfeita com a compra até que surja um novo desejo necessário.

Como nos explica Oliveira (2005, p. 117) "uma publicidade objetiva fazer correlações imediatas entre o que é visto e o sentido, entre o sensível e inteligível”. Devido à duração do filme publicitário analisado ser de 30 segundos, o tempo de leitura é curto. A publicidade veiculada na televisão conta com um recurso específico de expressão caracterizado pela dinâmica, velocidade, atratividade que é diferente da revista ou do outdoor.

Dessa forma esses 30 segundos de duração da publicidade devem ser muito bem aproveitados, organizados e produzidos. Além do alto custo da veiculação de um comercial na televisão, uma qualidade mal explorada ou um conceito ambíguo, por exemplo, pode ocasionar uma grave falha de comunicação dos ideais da campanha e da empresa contratante. Nesse sentido, objetivamos conduzir esta análise nos seus principais detalhes.

O comercial da Nissan começa com uma música eletrônica com batidas fortes e bem definidas, a trilha musical usada é a canção Crazy do grupo Gnarls Barkley. Logo em

\footnotetext{
${ }^{1}$ Disponível em: <http://www.nissancrazy.com.br/cvt/site/campanha.asp>, acesso em: 20/04/2007.
} 
seguida, tem início a narração em off que é feita por uma voz feminina simultânea ao movimento da câmera que dá um close no olhar atento de um homem para alguma coisa.

O cenário é uma imagem em preto e branco que se caracteriza por uma chuva constante. Os movimentos e as reações do homem acompanham a narração, o detalhe das gotas da chuva caindo são mostrados. Imagens fragmentadas do carro aparecem rapidamente. A sintonia entre a fala do narrador e as ações da personagem continua até o momento em que acontece uma ruptura ocasionada pela visualização do carro que entra no enquadramento da cena. A trilha musical, a narração, a chuva e a personagem parecem reagir à situação construída por meio da aparição completa do carro, localizado de um lado da rua, enquanto a personagem está em outro. Se olharmos com atenção, percebemos que apenas o carro é colorido.

O curso natural da chuva é invertido. O homem que estava fraquejando encostado ao muro, agora aparece em pé, no mesmo local da rua, em lugar oposto ao do carro. Sua atitude é a de um observador. A narração termina com uma frase de efeito, outros modelos da Nissan são mostrados, marca, slogan e site da campanha são apresentados em fundo preto e a trilha musical termina com o final da publicidade.

\section{Imagens do filme publicitário}


CASA, Vol.5, n.2, dezembro de 2007
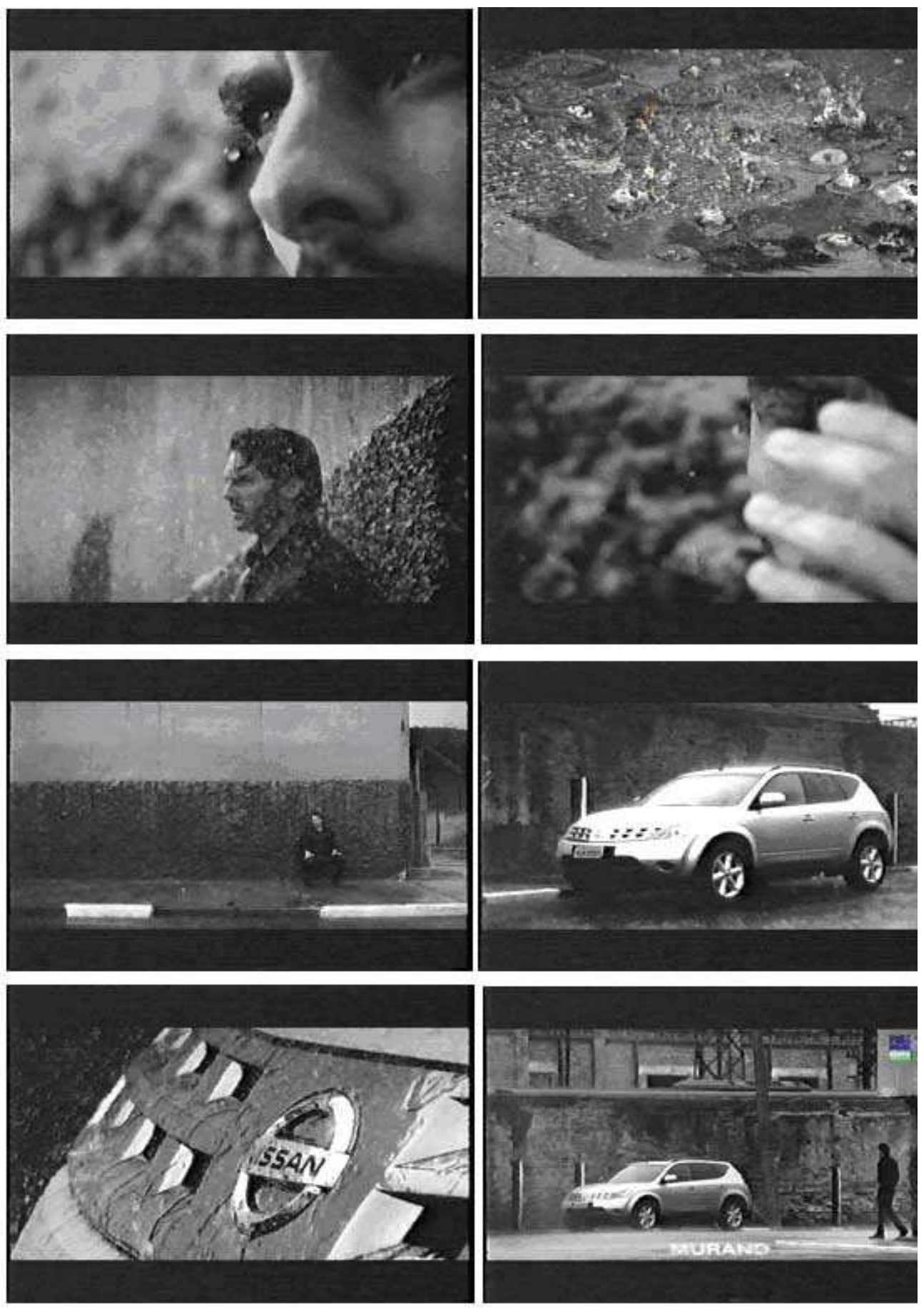

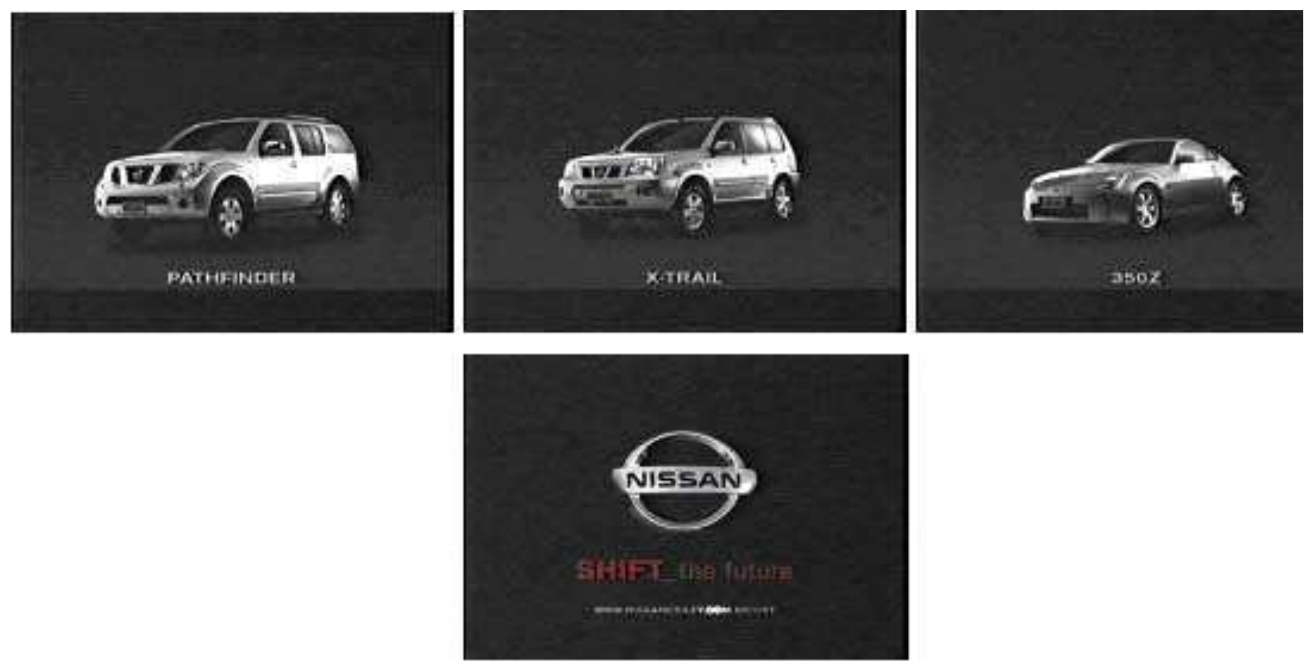

\section{A narração}

Antes de analisar todo o conteúdo apresentado pelo narrador no texto publicitário, vamos compreender as principais especificidades quanto ao uso desse recurso. A narração é antes de tudo uma fala dirigida a um destinatário, sendo que as escolhas do seu discurso sempre buscam um efeito. O narrador é bem articulado, não comete erros, não gagueja; seu discurso é elaborado para que a sua comunicação seja feita com clareza e com o objetivo de transmitir o efeito de verdade.

A narração no filme publicitário da Nissan é de alguém imponente que não vemos, não conhecemos e não não temos como contestar; é feita por uma voz feminina que fala diretamente da personagem e para a personagem. Sua fala é a seguinte:

Primeiro é uma ansiedade, um calor no peito que quase sufoca. O estômago congela, as mãos ficam suadas e os pensamentos ficam confusos. Os joelhos tremem e você mal se sustenta... Você tá louco! Louco por um Nissan. E é assim que vai ser daqui pra frente.

O narrador é figurativizado ${ }^{2}$ como uma mulher que se mostra segura de si, é dominadora, provocadora e até chega a menosprezar a personagem. Essa figurativização de mulher é construída por seu discurso e sua voz atraente como um sujeito competente. Não se trata de qualquer mulher, a entonação, o tom e o ritmo da sua voz asseguram essa caracterização. É essa mulher que dita os fazeres da personagem, as suas reações e as suas aflições, em suma, o seu estado emocional. A mulher faz mais do que prescrever o que a personagem sente no presente (o estômago congela, as mãos ficam suadas), é ela quem atesta o estado de loucura (você tá louco), é, também, quem o condena à loucura pelo carro, pelo resto de sua vida (e é assim que vai ser daqui pra frente). A fala do narrador é prescritiva e, aparentemente, é incontestável e incontestada pela personagem-homem.

\section{O percurso da personagem-homem}

A personagem - sujeito da publicidade - é figurativizada como um homem na faixa dos 30 anos, que usa roupas pretas (camisa, calça e sapato), não faz a barba diariamente,

\footnotetext{
2 “No arranjo da figuratividade, as formas de adesão e de convencimento são instaladas na estruturação do objeto visível, por meio dos distintos simulacros ou mundos de mundos nele arquitetados. A figutarividade, que Greimas define como 'a tela do parecer', ao formar os simulacros, permite conhecer nos textos visuais os mecanismos do dizer verdadeiro, da construção de dado efeito de verdade, mentira, ou segredo, que articulam a produção do crer” (OLIVEIRA, 2005, p. 116).
} 
talvez pelas novas influências da moda, segundo a qual possuir um estilo despojado é "estar na moda", ou, talvez, seu trabalho não o obrigue a estar barbeado todos os dias; ou ainda, ele é um sujeito que perdeu a auto-estima e não se importa mais com sua aparência.

Ele aparece em pé, na chuva, ansioso, com dificuldades de respiração, mãos suadas, confuso, pernas bambas, que nem o sustentam suficientemente. A partir do contexto da cena, deduzimos que ele está sob o efeito de alguma emoção ou de alguma substância que altera o seu comportamento. Podemos interpretar que ele se encontra em um estado de êxtase profundo, de paixão pelo carro.

De acordo com Landowski (2005, p. 97), o efeito do acidente patêmico "é, em suma, fazer por um momento perder a razão àquele que é, conforme toda a aparência, sua vítima impotente. Tais são os efeitos devastadores da paixão!" e complementa dizendo que "a dimensão passional apresenta-se efetivamente, como a negação do racional e do cognitivo". A personagem perdeu a noções do que fazer e do que ser.

É plausível interpretar que a personagem encontra-se em estado patêmico, pois nos instantes que precedem o encontro com o objeto - motivo de sua atração, desejo e paixão - ele está sentindo as mãos suadas, o estômago congelado, os joelhos tremerem, calor no peito, etc. Nesse instante, a razão do sujeito dá lugar a sua emoção por estar ali atraído pelo objeto.

O sentido de loucura construído nessa publicidade é interpretado como algo eufórico, pois tira o sujeito da cotidianidade, do mundo das privações e das obrigações. Esse sujeito quando está "louco" esquece que possui problemas e obrigações, deixando-se conduzir pela sonoridade da trilha musical e da voz feminina que o atrai. Ele pode até se dar ao luxo de andar na chuva quando bem entender.

Mas isso não basta! Aos poucos o efeito vai passando, segue-se a lentidão pósconjunção com a loucura e o sujeito entra novamente na cotidianidade. E como alguém covarde para quem não bastou viver, por uns instantes, o momento estésico proporcionado por um "não sei o quê" (loucura? paixão?), ele se curva, sente os joelhos tremerem, dobrarem-se e mal consegue se manter em pé.

Nesse contexto, uma voz feminina e muito sensual, mas autoritária e manipuladora, encontra o estado ideal para atuar e conduzir a personagem à conjunção com a duração sem fim da perfeição da loucura, a fusão total e vitalícia do sujeito com o objeto de valor loucura figurativizado pelo carro Nissan.

Nesse momento acontece a ruptura, momento em que aparece o carro, a trilha musical é intensificada e a fala do narrador é mais enfática. Todos esses elementos reiteradamente conduzem a personagem à conjunção sem fim e sem volta com a loucura pelo Nissan. Esse homem que se mostrou a deriva o tempo todo, busca forças, coloca-se em posição ereta e não vai ao encontro do seu objeto de desejo. Ele se mantém a distância como um observador que se conforma em apenas olhar "a uma boa distância".

\section{A trilha musical}

A trilha musical utilizada no filme publicitário é a canção Crazy do grupo Gnarls Barkle. A trilha musical está presente em toda a publicidade e não é suprimida por um só instante. Desde o início ela acompanha a narração e a personagem com batidas fortes, bem definidas. Pela escolha dessa trilha musical percebemos que a música eletrônica, a qualidade da voz do cantor, o trecho da letra recortado e o nome da canção Crazy (louco) nos mostram claramente que o tema loucura é mais uma vez o alvo do enunciador da Nissan. Nessa publicidade o enunciador escolheu o trecho da letra onde é cantado por três vezes 
seguidamente este verso: "Does that make me crazy? Does that make me crazy? Does that make me crazy?" (Isso faz de mim louco? Isso faz de mim louco? Isso faz de mim louco?)

É no exato momento em que acontece a narração, a atuação da personagem e a aparição do carro que a melodia é intensificada com a letra. A canção é cantada para o carro. É no instante em que o homem olha para o carro que o verso é cantado. O verso cantado é uma pergunta e a colocação de uma pergunta sempre coloca uma escolha: sim ou não. Nesse verso cantado o intérprete se pergunta: "Does that make me crazy?". É como se essa pergunta tivesse sido feita pela própria personagem. O pronome demonstrativo 'isso' faz referência ao objeto de valor carro. Para que não fiquem dúvidas de que é 'isso (o carro) que faz da nossa personagem um homem louco, a fala do narrador nos esclarece: "Louco por um Nissan".

\section{O cenário e a construção do objeto de valor}

É em uma brecha da urbanidade que nos é apresentado o cenário onde se desenvolverá o filme publicitário. Em uma rua asfaltada onde o acinzentado do céu resplandece no chão e nas paredes, as cores do vídeo variam na escala entre o preto e o branco. Nessa rua chove. Uma chuva que perdura por todo o tempo. Não começa a chover com o início do comercial, somos levados a crer que já chovia muito antes do início, pois há poças de água no chão. Nesse cenário, apenas a personagem e o carro estão presentes, não há mais ninguém, nada e nenhum outro elemento pode atrapalhar o encontro dos dois; a existência de um é pré-condição para a presença do outro.
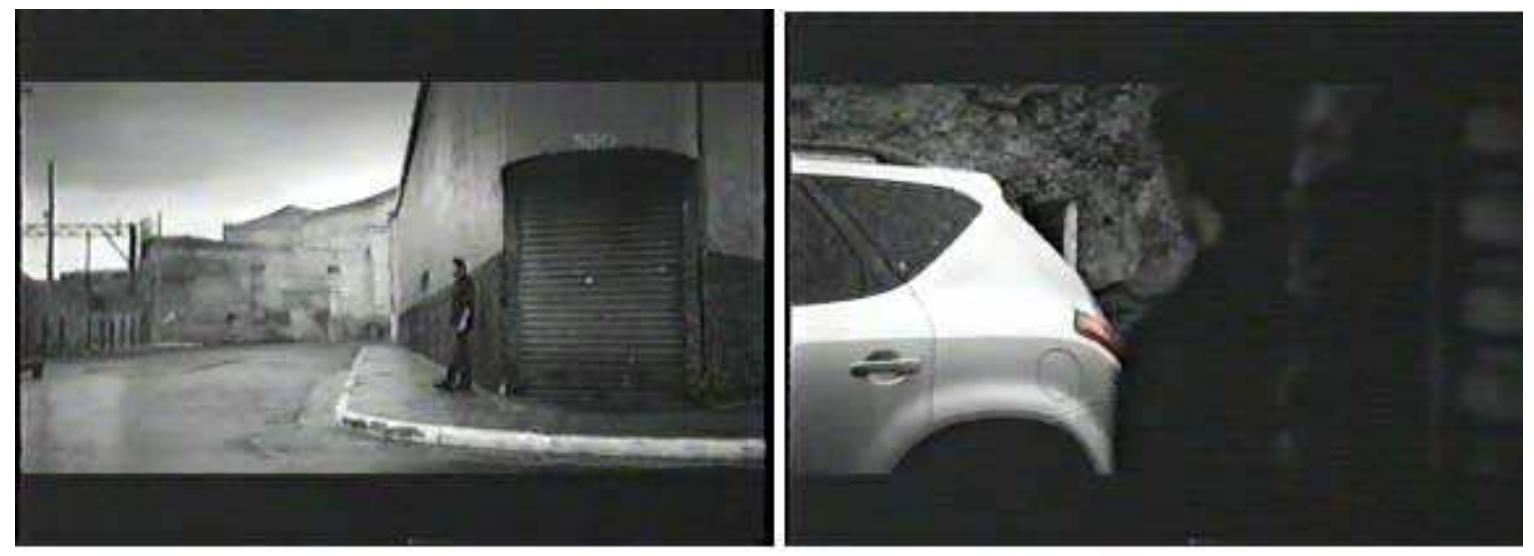

A chuva que cai ininterruptamente, as cores preta e branca, além da caracterização da personagem, são partes integrantes da construção do cenário que não tende a ser o mundo colorido e vivo que estamos acostumados a ver, por exemplo, nas figurações "cor-de-rosa" das novelas ou dos comerciais que exploram a perfeição da vida. Nesse mundo criado no filme publicitário como disfórico, apenas o carro Nissan-Murano possui cores.

$\mathrm{O}$ carro se mostra como algo que sobrevive às adversidades do lugar. Pelo fato de ele possuir cores e, sobretudo, por ele interferir de modo efetivo quando da sua aparição, ele modifica o ambiente. Percebemos isso pela influência que o carro exerce sobre o homem que estava fraquejando e se levanta, e sobre a chuva que estava caindo e muda sua direção. Interpretamos que o carro enquanto objeto de valor construído nos dá força e é algo sobrenatural.

\section{Os efeitos do vídeo}

Até a chuva inverte o seu curso natural e começa a "cair para cima" (chove do chão para o céu). $\mathrm{O}$ enunciador, com o objetivo de destacar o momento da aparição completa 
e única do carro, através dos recursos do vídeo, inverte a queda da chuva e faz chover para cima; entretanto acaba dispensando um importante detalhe. Ele faz com que a personagem não conclua a conjunção com o objeto através da aproximação com o mesmo. Expliquemos: o homem e a chuva são os únicos que podem se movimentar. O carro está parado do outro lado da rua. A chuva está caindo normalmente, assim o homem tende a caminhar para frente em direção ao carro. Quando o filme começa a ser reproduzido de trás para frente, a chuva começa a subir do chão para o céu, invertendo o seu curso natural e o homem que esboçava uma aproximação do carro, da mesma forma, age de modo inverso. Sua ação é retrocedida como a ação da chuva e ele se afasta fisicamente do carro, seu objeto de valor por excelência.

Esse é o instante de culminância da tensão, pois, a partir dele, acontece algo inesperado. É o momento da contemplação e da conjunção completa da personagem com o Nissan-Murano, momento este que, de tão especial que é, é capaz de mudar a ação da natureza e afastar o sujeito que até então só olhava. Agora ele continua olhando e se afastando.

\section{Um olhar semiótico}

$\mathrm{Na}$ apresentação do livro de Semprini (2006, p. 13), afirma-se que a teoria semiótica é testada pelo autor como "teoria da significação das construções das organizações dos procedimentos do mercado". Para ele, a natureza semiótica da marca é entendida como a capacidade de construir e veicular significados.

As construções narrativas organizadas como a publicidade e como a comunicação comercial são atos discursivos; e "é exatamente nesses atos discursivos que reside a verdadeira natureza da marca" (SEMPRINI, 2006, p. 106). No discurso da marca encontra-se a construção de sua identidade, sua postura diante de seus consumidores, a maneira pela qual a marca quer ser vista e reconhecida pelos destinatários, a sua história e seu desenvolvimento.

Entendemos por discurso todo enunciado ou texto manifesto. O próprio objeto é um discurso em si, pois passou por um processo de enunciação - que são as práticas de colocação em discurso -, que o modelou, organizou e definiu suas características "segundo uma estratégia enunciativa definida por um enunciador e dirigida, (...) aos destinatários" (SEMPRINI, 2006, p. 104). A marca Nissan pode ser entendida como um objeto-discurso por possui uma história e uma estética, o que faz com que a marca seja mais do que um objeto de comunicação. A marca é um objeto discursivo, pois é por meio do discurso que se torna "diferente e interessante aos olhos do consumidor, que justifica seu valor agregado e que inaugura e mantém uma relação com a marca”. (SEMPRINI, 2006, p. 105).

A necessidade de injetar novos sentidos - buscada pelo discurso inovador - faz com que o enunciador da Nissan crie na campanha e, mais precisamente, no filme publicitário um mundo possível, o da loucura em preto e branco, onde a loucura inverte o seu significado semântico usual disfórico e passa a ser um mundo da loucura eufórico. A estrutura da narrativa é simples e linear. Temos o ator (sujeito) em disjunção do seu objeto de valor carro. No percurso performático do sujeito, para atingir o objeto de valor, temos a erotização das relações entre sujeito e narrador. O sujeito é dominado e manipulado por sedução e intimidação em direção ao carro.

Situação inicial: Suj. em dis(junção) com O.v

Situação final: Suj. em con(junção) - por meio do olhar, do desejo - com O.v 
Por "mundo possível", citado acima, entendemos que é toda construção de sentido organizada na qual confluem "elementos narrativos, fragmentos de imaginário, referências sócio-culturais, elementos arquétipos, e qualquer outro componente que possa contribuir para tornar este mundo significativo para o destinatário" (SEMPRINI, 2006, p. 21). Na publicidade da Nissan é criado o simulacro da loucura eufórica que a personagem vive, pois está apaixonado, contagiado pelo Nissan-Murano.

Iremos buscar nas fraturas $^{3}$ os procedimentos para descrever o momento da ocorrência estética - estésica. Assim como nas fraturas, a personagem-sujeito é alguém em estado privação (em falta de algo), sendo assim, uma situação que seja insustentável é criada e, de certa forma, força o sujeito a procurar uma saída - um valor estético - que o tire desse estado. Nesse contexto, Greimas (2002, p.14) nos diz que "os valores estéticos são os que melhor repelem a negatividade, os únicos, talvez, que nos 'arremessam para o alto'."

É criado um cenário figurativo ideal para a aparição e a contemplação do objeto de valor, "uma convergência de circunstâncias". Pode-se perceber que não foi arbitrária a construção disfórica feita pelo enunciador da publicidade. Acontece a inversão de papéis entre sujeito e objeto. É o Nissan-Murano que agora é sujeito do fazer e exerce sobre o homem o seu fascínio (personagem muda e sem atitude), além de modificar a ação da natureza com a inversão do fluxo da chuva:

como se vê, trata-se de uma inversão completa dos papéis; enquanto (...) é o sujeito que, na apreensão estética, tem um papel ativo e empreendedor, e o objeto solicitado se dirige às vezes na sua direção, (...) é o objeto que é "pregnante"; mais ainda, é ele que exala a energia do mundo, e bem aventurado é o sujeito se lhe ocorrer encontrá-lo em seu caminho. (GREIMAS, 2002, p. 51).

Nesse momento em que a apreensão estética está em seu instante "culminante" e "insustentável" espera-se que o homem assuma sua posição de sujeito e vá ao encontro do seu objeto de valor. É para isso que o Nissan-Murano está na publicidade, para ser algo possível, alcançável, atingível, comprado em qualquer concessionária Nissan. Não apenas para ser olhado a uma "boa distância". Não deixamos de lado que o olhar de alguém que deseja é uma forma de conjunção com o objeto, mas a visão é, entre os sentidos, o mais superficial. O (con)tato, o prazer de dirigir, a interação possível entre homem-máquina, as qualidades e especificações do carro não são abordadas; é muito provável que esse nem seja o interesse dessa publicidade que explora o imaterial ${ }^{4}$ da marca Nissan.

Voltando ao momento em que a presença da estesis atingiu seus limites, o sujeito diante de seu objeto de valor, contempla-o na sua plenitude, deseja-o. Esse objetocarro que lhe dá forças para reerguer-se, muda o ambiente ao seu redor e, como nos informa a narração, além de o sujeito estar louco (no momento), está prestes a assumir este estado para o resto de sua vida. Nesse exato momento "o sujeito está prestes a dissolver-se em um mundo excessivo" (GREIMAS, 2002, p. 53). É no procedimento da filmagem e da edição que ele retrocede nas suas ações assim como a chuva. A personagem recusa fisicamente o objeto, a interação de corpo e alma não acontece, ou seja, é a "recusa do demasiado pleno e do demasiado próximo. Recusa inconsciente, reflexo da autodefesa diante do insustentável" (GREIMAS, 2002, p. 53).

\footnotetext{
3 “A descrição abarca o que precede o encontro entre sujeito e objeto (momento de disjunção), o próprio encontro em sua breve duração (momento de fusão de papéis) e o que o segue (retorno à disjunção)", conforme prefácio de Greimas (2002, p. 10).

${ }^{4}$ Cf. apresentado por Gors (2005).
} 
Não é o mundo da perfeição e da medida, mas aquele do excesso, que invade e ameaça absorver o sujeito - o mundo da loucura vitalícia. Compreende-se que o sujeito está prestes a entrar num mundo de tal modo exorbitante, sem volta, arriscado, porém que pode ser prazeroso ao extremo, mas de certa forma desconhecido. Essa publicidade pode ser analisada da seguinte maneira:

Alguém, o modelo, expõe-se, hiperbolicamente, em estado de êxtase, devido à presença, ao seu lado, de alguma coisa, o produto, objeto de seu desejo, sob o olhar de um terceiro, testemunha necessária, ora figurada na imagem, ora projetada fora dela, exatamente no lugar em que você, leitor, se encontra, olhando a cena. (LANDOWSKI, 2006, p. 14)

O dispositivo triangular arquétipo, termo utilizado pelo autor, explicado acima pode ser visualizado a seguir:

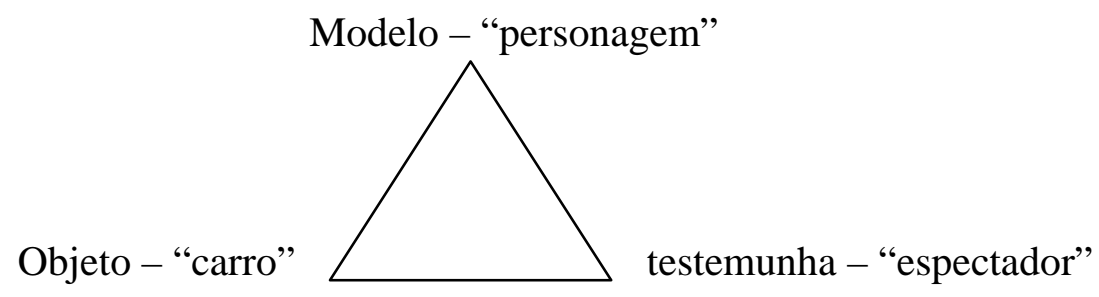

As próprias relações da personagem com o carro, como "o prazer de dirigir um Nissan", são omitidas para exaltar a relação erótica de submissão da personagem-homem à dominação exercida pelo narrador-mulher. Aqui acontece uma redução das relações do sujeito com o objeto para a erotização com o narrador, "nossas relações qualitativas com os objetos do mundo encontram-se, dessa maneira, rebaixadas numa única dimensão, aquela de relações eróticas fantasiadas com o outro" (LANDOWSKI, 2006, p.18).

As tentativas de mostrar estados de loucura, paixão, embriaguez não são fáceis de traduzir para uma linguagem. É muito difícil expressar tais sensações ou emoções por meio de palavras, imagens e sons. Esses estados de alma são da ordem do vivido, do sentir de cada sujeito, portanto algo pessoal. Na tentativa de expressar o estado de loucura, o enunciador dessa publicidade decide que o sujeito, a narração e a trilha musical serão instalados na enunciação com o mesmo objetivo, qual seja, figurativizar o tema da loucura e demonstrar o estado emocional da personagem. Ora, caso a encenação do estado emocional do sujeito não convença, a trilha musical ajuda, e, se mesmo assim ficar alguma dúvida do que o sujeito vive, a narração nos esclarece com todas as letras: "Você tá louco".

A reiteração serve como marcação das intenções que o enunciador da publicidade da Nissan objetiva que seja entendido pelo destinatário do discurso quando assistir à publicidade. Essa forma reiterada prima pela certeza de que o efeito de sentido (loucura, paixão) que é vivido pela personagem seja depreendido pelo enunciatáriodestinatário, pois todas as formas de expressão simultaneamente - a fala, a trilha musical e a imagem - comunicam quase que o mesmo conteúdo. A finalização do filme prescreve uma só direção: "E é assim que vai ser daqui pra frente" - até que uma nova campanha seja lançada.

\section{Valorização da marca}

A partir da análise dessa publicidade é possível delinear um dos caminhos de como se apresentam as publicidades de automóveis nos últimos anos. A publicidade da Nissan não faz referência às características técnicas do carro nem de seu preço; o carro não é 
apresentado como um valor de $u s o^{5}$, ou seja, as características como segurança e dirigibilidade são omitidas, o carro não é valorizado enquanto meio de transporte, também não temos um condutor dirigindo. Na publicidade da Nissan temos uma história que é vivida por uma personagem e não uma representação das características utilitárias do veículo.

Vimos como o objeto-carro ganha características de sujeito por ser capaz de mudar o curso natural da chuva e fortalecer e exercer fascínio de quem o olha. Quando o Nissan-Murano figurativiza a própria identidade de seu consumidor, seu status social, sua masculinidade, a sensibilidade, a emoção e o fascínio que o carro exerce sobre a personagem, ele se torna num valor de base ${ }^{6}$. A publicidade da Nissan mostra como ocorre a construção do ser do sujeito por possuir o carro. É o Nissan-Murano que permite ao sujeito ser alguém emocionado, apaixonado, sensibilizado, fascinado. O tipo de relação expressa é da ordem do ter para ser.

Após contrapor os valores de base e os valores de uso chegamos à demonstração dos quatro tipos de valorização presentes na comunicação publicitária de automóveis propostos por Jean-Marie Floch a saber: a valorização prática, utópica, lúdica e crítica. Por meio da priorização dos valores de base presentes na publicidade analisada, a valorização lúdica da marca é constatada pelas seguintes características: essa publicidade trabalha com a exploração do sensível, do valor sentimental, do estado patêmico que a personagem vive, da encenação de uma "pequena loucura", do luxo, do refinamento. Esses elementos asseguram a preponderância da valorização lúdica em relação às demais. Os sentidos da personagem são convocados pela visão do carro; o design da parte externa do veículo é valorizado pelas tomadas de câmera que permitem que o destinatário veja os detalhes do objeto que é causador dos estados de alma e de ânimo que vive a personagem: pelo olfato que exala quando chove nos centros urbanos; pela taticidade, as mãos suadas que são levadas ao rosto molhado pela chuva. O carro não é um simples instrumento, ele faz emocionar.

\section{Referências bibliográficas}

FLOCH, Jean-Marie. Semiótica, marketing y comunicación - Bajo los signos, las estrategias. Barcelona: Paidós, 1993.

Alguns conceitos fundamentais em semiótica geral. In: Documentos de estudo do

Centro de Pesquisas Sociossemióticas, 1. São Paulo: Edições CPS, 2001.

FONTANILLE, Jacques \& GREIMAS, Algirdas Julien. Semiótica das Paixões. São Paulo: Àtica, 1993.

GAGE, Leighton D. \& MEYER, Cláudio. O filme publicitário. São Paulo: SSC\&B - Lintas, 1985.

\footnotetext{
${ }^{5}$ Conforme Floch (1993, p. 145) quando o carro é valorizado como modo de transporte (seguro, confortável, boa dirigibilidade, etc), esses traços caracterizam os valores de uso; as características materiais e mecânicas do veiculo são enfatizadas.

${ }^{6}$ Agora, é por meio do objeto que o consumidor é qualificado e reconhecido; o objeto lhe atribui status social e prestigio; é preciso ter o carro para ser como o sujeito figurativizado na publicidade. As características técnicas do objeto não importam. O que é considerado são os investimentos discursivos feitos sobre o objeto anunciado.
} 
CASA, Vol.5, n.2, dezembro de 2007

GORS, A. O imaterial. São Paulo: Annablume, 2005.

GREIMAS, Algirdas Julien. Da Imperfeição. Tradução. Ana Claudia de Oliveira. São Paulo: Hacker Editores, 2002.

LANDOWSKI, Eric. O triangulo emocional do discurso publicitário, in: Comunicação Midiática n6. Bauru: UNESP, 2006, p.14.

Para uma semiótica sensível. In: Educação e Realidade vol.30, n². 2005.

Presenças do outro. Tradução. M. Amazonas. São Paulo: Perspectiva, 2002.

LOPES, Ivã Carlos \& HERNANDES, Nilton (orgs.). Semiótica: objetos e práticas. São Paulo: Contexto, 2005.

OLIVEIRA, Ana Claudia de. Visualidade entre significação sensível e inteligível. In:

Educação e Realidade vol.30, $\mathbf{n}^{0} 2.2005$.

SEMPRINI, Andrea. A marca pós-moderna: poder e fragilidade da marca na sociedade contemporânea. Tradução. Elisabeth Leone. São Paulo: Estação das Letras, 2006. 